\section{Commentary: Preventing the virulent lethality of ascending aortic aneurysm}

John A. Elefteriades, MD, PhD (hon), and

Bulat A. Ziganshin, MD, PhD

Czerny and colleagues ${ }^{1}$ have provided a thoughtful, insightful review of guidelines for intervention for ascending thoracic aortic aneurysm (TAA).

Czerny and colleagues ${ }^{1}$ have, appropriately, shined a focus on aortic length (annulus to base of innominate artery), on which our group has been concentrating as well. ${ }^{2}$ Length has the distinct advantage that it does not change at the moment of aortic dissection. So, in contrast to diameter (which does change acutely), the length we see after dissection was the length just before dissection. This constant nature of aortic length makes it ideal as a variable for evaluation as an intervention criterion.

Two fundamental issues regarding further refinement of surgical intervention criteria are brought to mind by this overview:

1. "Natural history of TAA" is becoming no longer discernible. Heisenberg's uncertainty principle tells us that when a particle physicist tries to locate an electron, the very process of measurement influences the localization $^{3,4}$ (Figure $1^{5}$ ). In other words, the process of measurement disturbs the item being measured. We face a similar conundrum in care of the thoracic aorta. In coming to understand the behavior of the aorta, we have implemented preemptive surgical therapy that no longer allows the natural history to be expressed. We operate before the aorta has a chance to dissect. Many of us now operate at $5.0 \mathrm{~cm}$, following an evidence-based "left shift" toward preemptive surgery

\footnotetext{
From the Aortic Institute at Yale-New Haven Hospital, Yale University School of Medicine, New Haven, Conn.

Disclosures: J.A.E.: Principal, CoolSpine; Consultant for CryoLife; Data/Safety Monitoring Board for Terumo. The other author reported no conflicts of interest.

The Journal policy requires editors and reviewers to disclose conflicts of interest and to decline handling or reviewing manuscripts for which they may have a conflict of interest. The editors and reviewers of this article have no conflicts of interest.

Received for publication Feb 8, 2021; revisions received Feb 8, 2021; accepted for publication Feb 9, 2021; available ahead of print Feb 19, 2021

Address for reprints: John A. Elefteriades, MD, PhD (hon), Aortic Institute at Yale New Haven, Yale University School of Medicine, 789 Howard Ave, Clinic Building CB317, New Haven, CT 06510 (E-mail: john.elefteriades@yale.edu).

J Thorac Cardiovasc Surg 2022;163:2031-3

$0022-5223 / \$ 36.00$

Copyright (c) 2021 by The American Association for Thoracic Surgery

https://doi.org/10.1016/j.jtcvs.2021.02.046
}

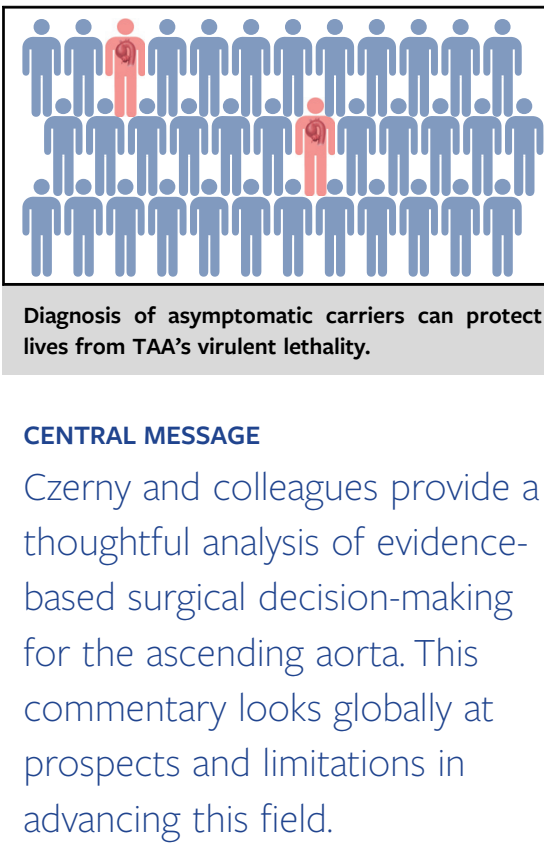

at smaller aortic diameters than before. ${ }^{6}$ So, we are now preempting the natural behavior of TAA, no longer allowing the aorta the opportunity to dissect. Thus, for patients with a diagnosed TAA, the natural history is no longer fully in evidence. The days of observation of TAA into the now known "danger zone" are behind us.

2. Acute aortic dissection cases pose their own natural history dilemmas. So, our main opportunity to observe natural history of TAA is found in previously undiagnosed patients who present with sudden, unexpected type A aortic dissection. But, from a natural history standpoint, these patients are problematic. First, we do not know the date of onset of the aneurysm, so calculation of yearly event rates is hampered. Second, we do not know the size of the aneurysm just before it dissected, obfuscating development of intervention criteria. It is now becoming clear $^{7,8}$ that the aorta grows abruptly at the moment of aortic dissection by approximately $8 \mathrm{~mm}$ in our calculations. These calculations are based on those few patients who, fortuitously, happened to have a computed tomography scan for other reasons (usually for surveillance of lung nodules) in close temporal proximity to the time of onset of their aortic dissection (Figure 2). So, yearly growth rate and exact aortic size at the moment of aortic dissection are troublesome from an investigational standpoint. 


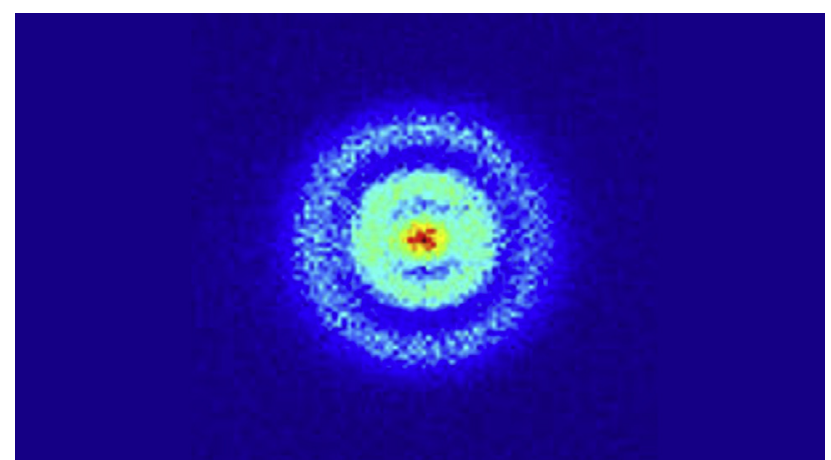

FIGURE 1. Image of a hydrogen atom's orbital structure. The electron can be anywhere in the orbital ring at any one time. Reproduced with permission from Stodolna and colleagues. ${ }^{5}$

Bespoke management based on molecular genetics is rapidly permitting personalized, data-driven aortic care, with a separate intervention size criterion for each specific mutation. A size "timeline" for such intervention is presented in Figure 3, A. ${ }^{9}$ This molecular-based guidance will become more prevalent, as new causative genes are discovered each year. Our suspicion is that, over the next 5 to 10 years, the majority of aortic root and ascending aortic aneurysms will be found to be associated with specific novel genetic mutations.

Another use of molecular data arises from information about the common age at which dissection occurs in specific genetic syndromes (Figure 3,B). Such precision geneticsbased age data can help to inform clinical decisions, because age at dissection tends to cluster for each specific genetic variant. ${ }^{10}$

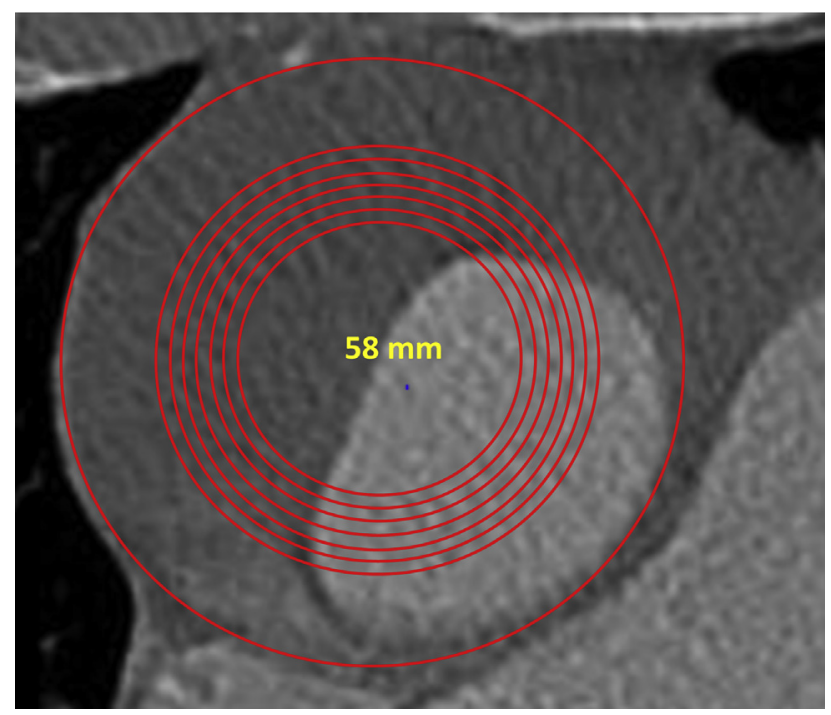

FIGURE 2. Serial computed tomography scans superimposed on a single image, with red circles demonstrating the diameter each year. Images were taken for follow-up of lung nodules. Note the 8-mm sudden enlargement occurring immediately after aortic dissection in the last year of follow-up.
While we pursue and encourage research into other nonsize criteria for surgical intervention (eg, biomarkers, artificial intelligence), no advances seem currently "ready for prime time." $11-13$

Besides fine-tuning criteria for surgical intervention, perhaps most important life-saving advance would reside in the diagnosis of silent TAAs. ${ }^{14-16}$ If we can diagnose the asymptomatic aneurysm carrier in the general population, even our present intervention guidelines will keep him/her quite safe. Diagnosis of asymptomatic carriers probably represents the most potentially impactful means to protect lives from the virulent lethality of TAA.

\section{References}

1. Czerny M, Rylski B, Della Corte A, Krüger T. Decision-making to perform elective surgery for patients with proximal thoracic aortic pathology: a European perspective. J Thorac Cardiovasc Surg. 2022;163:2025-30.

2. Wu J, Zafar MA, Li Y, Saeyeldin A, Huang Y, Zhao R, et al. Ascending aortic length and risk of aortic adverse events: the neglected dimension. J Am Coll Cardiol. 2019;74:1883-94.

3. Lumen. Chemistry for non-majors. Heisenberg Uncertainty Principle. Available at: https://courses.lumenlearning.com/cheminter/chapter/heisenberg-uncertaintyprinciple/. Accessed February 1, 2021.

4. Socratic Q\&A. Why is it impossible to know precisely the velocity and position of an electron at the same time? Available at: https://socratic.org/questions/ why-is-it-impossible-to-know-precisely-the-velocity-and-position-of-an-electron. Accessed February 1, 2021.

5. Stodolna AS, Rouzée A, Lépine F, Cohen S, Robicheaux F, Gijsbertsen A, et al. Hydrogen atoms under magnification: direct observation of the nodal structure of stark states. Phys Rev Lett. 2013;110:213001.

6. Ziganshin BA, Zafar MA, Elefteriades JA. Descending threshold for ascending aortic aneurysmectomy: is it time for a "left-shift" in guidelines? J Thorac Cardiovasc Surg. 2019;157:37-42.

7. Rylski B, Branchetti E, Bavaria JE, Vallabhajosyula P, Szeto WY, Milewski RK, et al. Modeling of predissection aortic size in acute type A dissection: more than $90 \%$ fail to meet the guidelines for elective ascending replacement. J Thorac Cardiovasc Surg. 2014;148:944-8.e941.

8. Mansour AM, Peterss S, Zafar MA, John A, Rizzo JA, Fang H, et al. Prevention of aortic dissection suggests a diameter shift to a lower aortic size threshold for intervention. Cardiology. 2018;139:139-46.

9. Vinholo TF, Brownstein AJ, Ziganshin BA, Zafar MA, Kuivaniemi H, Body SC, et al. Genes associated with thoracic aortic aneurysm and dissection: 2019 update and clinical implications. Aorta (Stamford). 2019;7:99-107.

10. Mariscalco G, Debiec R, Elefteriades JA, Samani NJ, Murphy GJ. Systematic review of studies that have evaluated screening tests in relatives of patients affected by nonsyndromic thoracic aortic disease. J Am Heart Assoc. 2018;7: e009302.

11. Wang Y, Barbacioru CC, Shiffman D, Balasubramanian S, Iakoubova O, Tranquilli M, et al. Gene expression signature in peripheral blood detects thoracic aortic aneurysm. PLoS One. 2007;2:e1050.

12. van Bogerijen GH, Tolenaar JL, Grassi V, Lomazzi C, Segreti S, Rampoldi V, et al. Biomarkers in TAA-the Holy Grail. Prog Cardiovasc Dis. 2013;56: 109-15.

13. Ostberg NP, Zafar MA, Ziganshin BA, Elefteraides JA. A machine learning approach for predicting complications in descending and thoraco-abdominal aortic aneurysms. New York, NY: Presented at: The American Association for Thoracic Surgery Aortic Symposium; April 23-24, 2020.

14. Tanaka Y, Sakata K, Sakurai Y, Yoshimuta T, Morishita Y, Nara S, et al. Prevalence of type A acute aortic dissection in patients with out-of-hospital cardiopulmonary arrest. Am J Cardiol. 2016;117:1826-30.

15. Moriwaki Y, Tahara Y, Kosuge T, Suzuki N. Etiology of out-of-hospital cardiac arrest diagnosed via detailed examinations including perimortem computed tomography. J Emerg Trauma Shock. 2013;6:87-94.

16. Elefteriades JA, Sang A, Kuzmik G, Hornick M. Guilt by association: paradigm for detecting a silent killer (thoracic aortic aneurysm). Open Heart. 2015;2: e000169. 


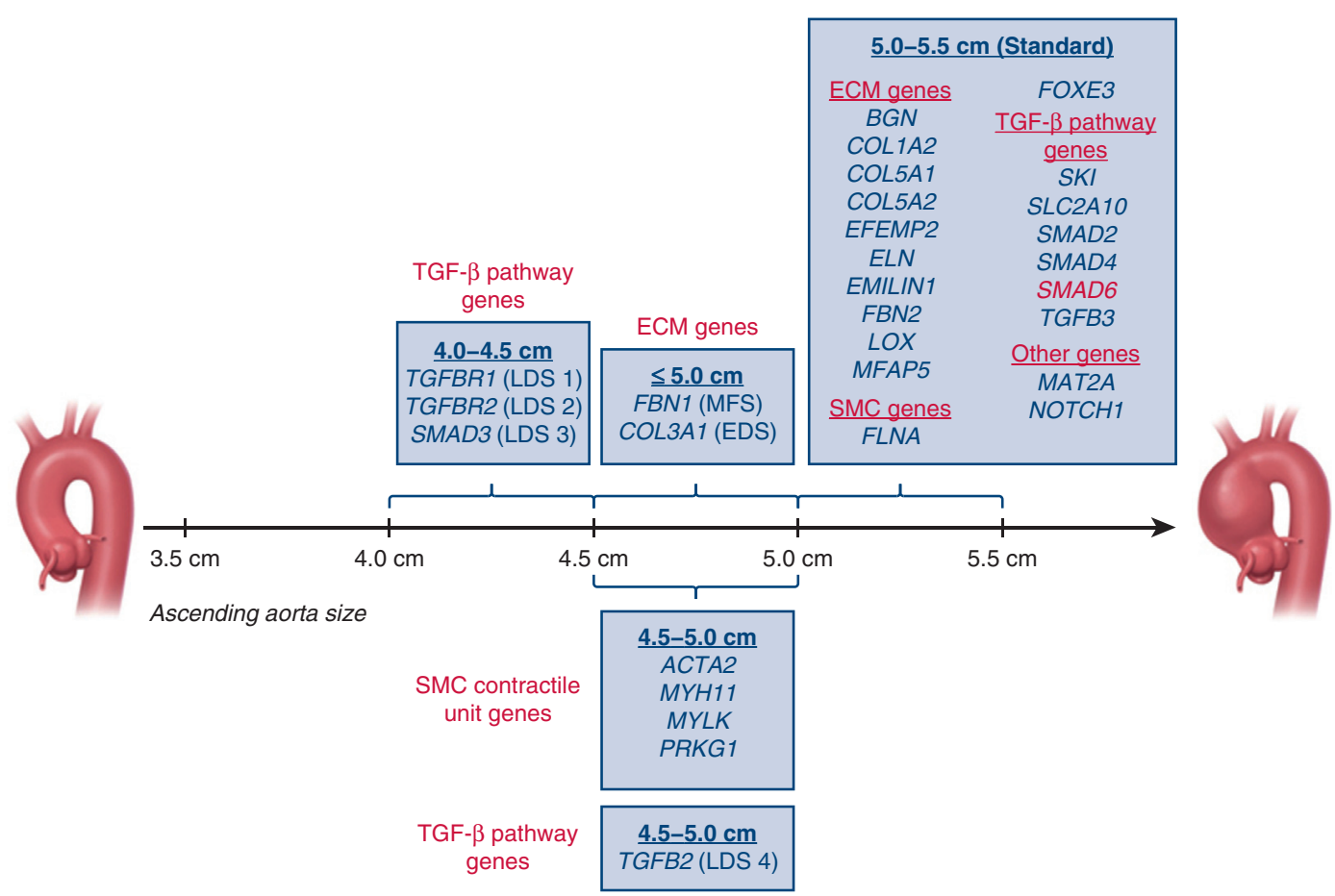

A

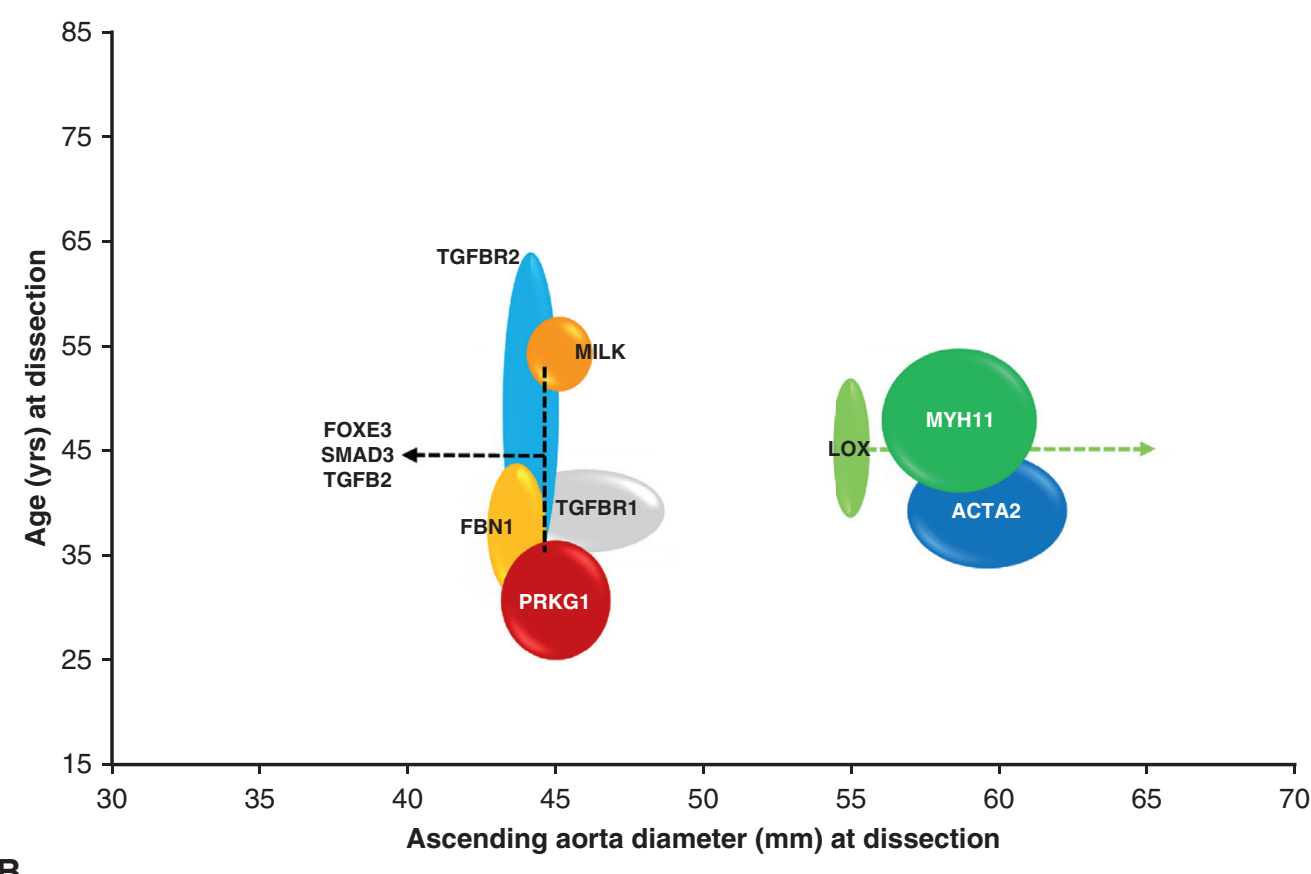

B

FIGURE 3. A, Size "timeline" for intervention based on specific causative mutation. Reproduced with permission from Faggion and colleagues. ${ }^{9}$ B, Schematic representation of genetic mutations with age and ascending aorta diameter at dissection. The widening of the circles/lines represents standard deviation in terms of age and diameters. Data are obtained from studies included in the systematic review. No numeric data were available for patients affected by aortic dissection regarding the genes NOTCH1 and MFAP5, and patients with MAT2A mutation did not experience aortic dissections. Reproduced with permission from Mariscalco and colleagues. ${ }^{10}$ 